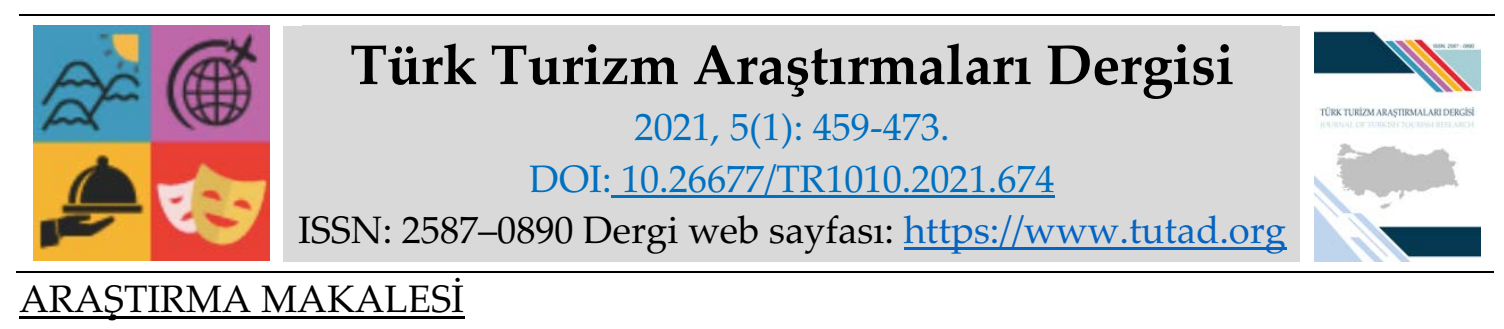

\title{
Kültürel, Gastronomik ve Turistik Değer: Muğla'da Arıcılık ve Özel Muğla Arıcılık Müzesi Örneği
}

Dr. Öğr. Üyesi Özer ŞAHIN, Muğla Sıtkı Koçman Üniversitesi, Turizm Fakültesi, Muğla, e-posta: ozer sahin@hotmail.com

ORCID: https://orcid.org/0000-0002-7497-564X

Prof. Dr. Ayşe AYDIN, Muğla Sıtkı Koçman Üniversitesi, Edebiyat Fakültesi, Muğla, e-posta: ayseaydin70@gmail.com

ORCID: https://orcid.org/0000-0001-5944-6347

Öz

Muğla tarih boyunca ünü denizaşırı ülkelere yayılan ve ticareti yapılan çam balı üretiminde bugün de söz sahibidir. Kentte arıcilık, turizmden sonraki en önemli sektördür. Bu makalede amaç arıcılığı kültürel ve turistik bir değer olarak ele almaktır. Bu çerçevede arıcılıktan nasıl yararlanılabileceğine, Türkiye'deki Gastronomi müzelerinden biri olan Özel Muğla Arıcılık Müzesi'nin nasıl geliştirilebileceğine yönelik bilgilere yer verilmiştir. Çalışmada ikincil ve birincil kaynaklardan yararlanılarak elde edilen veriler ışığında konu derinlemesine irdelenmiştir. Araştırmada nitel veri elde etme tekniği olan görüşme ve gözlem yöntemi kullanılmıştır. Verileri elde etmek için üç müze, bir arı çiftliği ziyaret edilmiş ve incelemelerde bulunulmuştur. Müzelerin yöneticileri, belediye çalışanları ve arıcılar ile yarı yapılandırılmış görüşmeler gerçekleştirilerek veriler elde edilmiştir. Elde edilen veriler elektronik ortama aktarılarak analizler gerçekleştirilmiştir. Neticede arıcılı̆̆ın turizm sektöründe önemli bir yere sahip olması nedeniyle; Muğla'da arıcılık, apiturizmi ve arıcılık müzesinde olması ve yapılması gerekenlere yönelik öneriler sıralanmıştır.

* Bu makale 16-19 Ekim 2019'da gerçekleştirilen 20. Ulusal Turizm Kongresi'nde sunulan bildirinin geliştirilmiş şeklidir.

Anahtar Kelimeler: Muğla Çam Balı, Özel Muğla Arıcılık Müzesi, Apiturizm, Gastronomi Turizmi, Gastronomi Müzeleri.

Makale Gönderme Tarihi: 02.01.2021

Makale Kabul Tarihi: 11.03 .2021

\section{Önerilen Atıf:}

Şahin, Ö. ve Aydın, A. (2021). Kültürel, Gastronomik ve Turistik Değer: Muğla'da Arıcılık ve Özel Muğla Arıcılık Müzesi Örneği, Türk Turizm Araştırmaları Dergisi, 5(1): 459-473.

(c) 2021 Türk Turizm Araştırmaları Dergisi. 


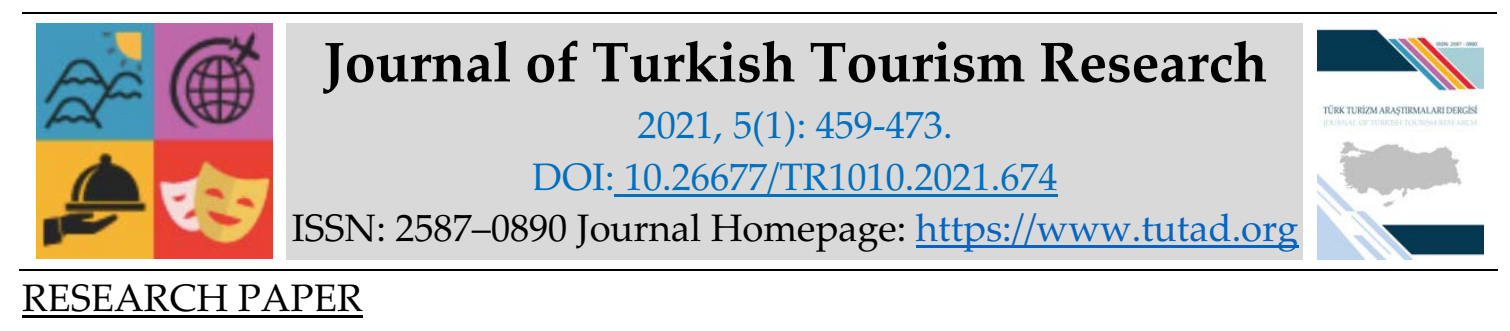

\title{
A Cultural, Gastronomic and Touristic Asset: Beekeeping in Muğla and Private Muğla Beekeeping Museum Case
}

Assistant Prof. Dr. Özer ŞAHIN, Muğla Sıtkı Koçman University, Faculty of Tourism, Muğla, email: ozer_sahin@hotmail.com ORCID: https://orcid.org/0000-0002-7497-564X

Prof. Dr. Ayşe AYDIN, Muğla Sıtkı Koçman University, Faculty of Literature, Muğla, e-mail: ayseaydin70@gmail.com

ORCID: https://orcid.org/0000-0001-5944-6347

\begin{abstract}
Muğla has been known in the world throughout history and is still known today in the field of pine honey production and trade. Beekeeping is the most important sector after tourism in the city and its districts. The aim of this study, beekeeping is discussed as a cultural and touristic value. In this context, how to benefit from beekeeping for apitourism and how to improve is one of the gastronomy museums in Turkey the Private Muğla Beekeeping Museum were discussed. In the present study, the subject was examined in depth in the light of the data obtained by using secondary and primary sources. In the research, interview and observation method, which is the technique of obtaining qualitative data, were used. In this respect, three museums and one bee farm were visited and inspections were made. Data was collected through semi-structured interviews held with the museum directors, municipality officers and beekeepers. The data obtained was transferred onto electronic environment and analyses were conducted. As a result of study, since beekeeping holds an important place in tourism industry, recommendations were made concerning beekeeping and apitourism in Muğla as well as what to keep and do in the beekeeping museum.
\end{abstract}

Keywords: Muğla Pine Honey, Private Muğla Beekeeping Museum, Apitourism, Gastronomy Tourism, Gastronomy Museums.

Received: 02.01.2021

Accepted: 11.03 .2021

\section{Suggested Citation:}

Şahin, Ö. and Aydın, A. (2021). A Cultural, Gastronomic and Touristic Asset: Beekeeping in Muğla and Private Muğla Beekeeping Museum Case, Journal of Turkish Tourism Research, 5(1): 459473.

(C) 2021 Türk Turizm Araştırmaları Dergisi. 


\section{Gİiş}

Arıcılık kültürel açıdan, arılara insan eliyle yapılan ilk müdahaleden itibaren başlayan ve nesilden nesile, çağa özgü değişikleri de içerecek şekilde aktarılarak günümüze ulaşan gelenek, görenek ve uygulamaları kapsamaktadır. Bal ise Prehistorik dönemden itibaren ritüellerde ve geleneksel tedavilerde kullanılan, beslenme geleneği ile halk edebiyatında çeşitli şekillerde yer alan kültürel bir üründür (http://www.muglakulturturizm.gov.tr; Yılmaz Erkovan, 2018).

Her yıl Türkiye'nin büyük oranda çam balı ihtiyacını karşılayan Muğla'da arıcılık, turizmden sonraki en önemli sektördür. Kent bazında bir taraftan arıcılık diğer taraftan turizm faaliyetleri yürütülürken, her iki sektörün iş birliği önem arz etmektedir. Bu çalışmada Muğla'da turizm çerçevesinde çeşitli yönleriyle değerlendirilebilecek arıcılık sektöründen apiturizm açısından nasıl faydalanılacağına dair, özellikle son on yılda artan sayıdaki Gastronomi müzelerinden biri olan Özel Muğla Arıcılık Müzesi'nin nasıl geliştirilebileceğine dair uygulanabilir öneriler sunulmaktadır.

Apiturizm son yıllarda popüler olmaya başlayan bir niş turizm pazarı olarak gelişmektedir. Bal sağlık amacıyla kullanılabilen, ilaçların yerini alabilecek doğal tedavi yöntemi olarak uygulanmaktadır. Apiturizm çerçevesinde propolis, arı ekmeği, arı sütü, polen ve balmumu gibi pek bilinmeyen ve kullanımı yaygın olmayan arı ürünlerine dikkat çekmek gerekmektedir. Arı ürünlerinin yemek pişirme, ilaç ve kozmetik alanındaki sık kullanımı, insana başarıyla hizmet edebilecek doğal ve sağlıklı yaşam tarzı sunmaktadır (Woś, 2014:68).

Bugüne kadar Muğla'nın müzecilik sektöründe operasyonel açıdan zayıf kaldığı söylenebilir ancak hali hazırda inşası devam eden Muğla Bölge Müzesi bu kültürel sektörü güçlendirecektir. Bu müze dişında küçük ve orta büyüklükte açllacak farklı branşlardaki diğer müzeler sektöre ayrıca güç ve değer katacaktır. Bu kapsamda çalışmada Özel Muğla Arıcılık Müzesi gastronomi turizmi çerçevesinde ele alınmış ve ilgili taraflara öneriler sunulmuştur.

\section{LITTERATÜR}

\section{Tarihsel Süreçte Arı ve Balın Kullanımı}

Bal arısının bitki nektarlarını topladıktan sonra işlemesi ve petekte depolaması sonucunda olgunlaşmasıyla elde edilen bal, doğal bir besindir ve Prehistorik dönemden itibaren insanoğlunun en önemli beslenme kaynakları içinde yerini almıştır. Paleolitik ve Mezolitik döneme ait kaya ve mağara resimleri, anılan dönemlerde bal avcılığı yapıldığını göstermektedir. Bal, Misır ve Mezopotamya'da tanrılara sunulmuş, tapınaklardaki kutsal hayvanların besin kaynağı olmuş, Persler'de tanrılar adına yapılan kurban törenlerinde kullanılmıştır (Zander, 1975:12; Şahinler, 2000:139; Lenger, 2010:89; Bulut, 2010:21; Bulut ve Lenger, 2015:7-8; Bulut, 2015:113).

Anadolu'da Neolitik dönemin önemli merkezlerinden Çatalhöyük'te bir duvar resminde yer alan çiçekler üzerindeki böcek tasvirleri balın arılar tarafından çiçeklerden toplandığının bilindiğini göstermesi açısından önemlidir (Mellaart, 2003:65). 1988 yılı Kültepe kazılarında ele geçen bir tablette evlilikle ilgili yapılan masraf listesindeki besinler içinde bala da yer verilmiştir (Albayrak, 2002:7, 10; Üreten, 2011:366). Hititlere ait Boyalı Höyük kazı buluntularından biri olan pişmiş topraktan yassı matara formlu bir şişe içinde bal, peteği ve çörekotu kalıntısı tespit edilmiştir. Hitit çivi yazılı belgelerinde balın fiyatı ve arıcılık ile ilgili suçlara yönelik bilgiler bulunmaktadır. Ayrıca dini nitelikteki metinlerden anlaşılan, balın tanrılara sunulan yiyecekler arasında ilk sırada yer aldığıdır. Hititlerde bal, genellikle bayram ve sunularda tüketilmek üzere yapılan ekmeklerde, ruhsal ve bedensel rahatsızlıkları iyileştirmek amacıyla yapılan ritüellerden 
Ammihatna Ritüeli'nde, ızgara çeşitlerinde, şarap ve biranın içine katılarak kullanılmıştır (Erkut, 2011:36-39; Üreten, 2011:367-373; Bulut ve Lenger, 2015:9).

İçeriğindeki yüksek oranda früktoz ve glikoz sebebiyle kolay hazmedilebilir bir karbonhidrat kaynağı olarak bal, Antik dönem mutfağında özellikle hamur işlerinde tatlandırıcı olarak; et, balık ve sebze yemekleri için hazırlanan soslarda, reçel yapımında, M.Ö. 1. yüzyıldan itibaren besinlerin bozulmasını önlemek amacıyla koruyucu olarak kullanılmış, farklı isimlerde alkollü içki ve sirke olarak tüketilmiştir. Bakteriyostatik ve bakterisidal özellikleri nedeniyle bal mutfağın yanı sıra tıpta, eczacılıkta, kozmetikte, parfüm yapımında, boya işlerinde, kuyumculukta, cenaze törenlerinde ve mumyalamada da hammadde olmuştur (Brown, 1993: 123; Curtis, 2001: 417-418; Dalby, 2003: 179-180; Lenger, 2010: 89-95; Lenger, 2011: 28-29; Ulusoy, 2012: 90-93; Bulut ve Lenger, 2015: 9-11; Bulut, 2016: 166-172; Harissis, 2017: 18). Balın istiflendiği peteklerden elde edilen balmumu ise aydınlatma, mühür yapımı, resim, boyama, bronz işleri, yazı araç gereci yapımı ve kozmetikte kullanılmıştır (Şahinler, 2000:141; Lenger, 2010: 89-90; Lenger, 2011: 29; Bulut ve Lenger, 2015: 12-13; Bulut, 2016: 172-173). Lüks tüketim maddesi olan en kaliteli ballar hoş kokuları, göz alıcı renkleriyle sunu nesnesi olarak da kullanım alanı bulmuş, böylece bal, üzerine dinsel ve sembolik değerler yüklenen ilahi sıvılardan biri haline gelmiş, kötülüklerden koruyucu olduğu kabul edilerek dini törenlerde ve cenaze merasimlerinde sunu içkisi olmuştur (Graf, 1980: 209-221; Lenger, 2010: 93; Lenger, 2011: 29).

Balın yanı sıra onu üreten arı da kutsal sayılmış, Mısır'da hem hanedanlığı hem de ülkeyi simgeleyen arı, Yunan panteonundaki Artemis başta olmak üzere Zeus, Apollon ve Demeter ile ilişkilendirilmiş, Roma panteonunda ise Mellona arıların ve arıcılığın tanrısı olmuştur (Sarı̈̈z, 2006: 13; Kahyaoğlu, 2011: 103; Bulut ve Lenger, 2015: 15; Harissis, 2017: 18). Ephesos antik kentinde basılan elektron sikkelerin ön yüzlerindeki arı tasviri Anadolulu ana tanrıçalardan Artemis Ephesia'nın ve kültünün merkezi Ephesos antik kentinin sembolü olmuştur (Tekin, 1992: 77-78). Avrupa'da 17. yüzyılda Roma ve Vatikan'ı yöneten Barberini Ailesi, arıyı aile armasında ve baskın bir görsel propaganda aracı olarak kullanmıştır. Napoleon ise arıyı endüstrinin ve çalışkanlığın sembolü olduğu için hanedan arması olarak tercih etmiştir (Kahyaoğlu, 2011: 102107).

Ege en çok rağbet gören balların üretildiği bölge olarak dikkat çekmektedir (Lenger, 2011: 29). Batı Anadolu'daki Ionia ve Aiolis bölgesi ballarıyla ünlüdür (Üreten, 2011: 379-380). Akdeniz kıyısındaki Lykia bölgesinde de arıcllı ve bal üretimi söz konusudur (Bulut, 2015: 101-103).

Anadolu'da Doğu Roma İmparatorluğu sınırları içindeki bölgelerde baldan şarap ve likör üretilmiş, her ikisi de sağlık amaçli içilmiş, bunun yanı sıra bal et kızartmalarında, salata ve zeytin başta olmak üzere yemeklerde, reçel, marmelat, helva ve tatlılarda kullanılmıştır. Kiliselerde yapılan ritüeller ve törenlerde ise sütlü bal ya da süt içildiği aktarılmıştır (Zalesskaya, 1990: 216220; Dalby, 2004: 79-214; Anagnostakis, 2013: 89-92; Doğer ve Armağan, 2014: 21-24; Germanidou, 2018: 93-100).

Osmanlı döneminde arıcılık bir ekonomik faaliyet olarak değerlendirilerek aşar vergisi alınmıştır. İlk Türkçe arıclık kitabı 1912 yılında yayımlanmış ve bunu diğerleri izlemiş, 1930'larda Ankara Teknik Tarım Okulu ve Gazi Çiftliği'nde arıcılık faaliyetlerine başlanmıştır. 1931 yılında gerçekleştirilen 1. Ziraat Kongresi'nde Türkiye'de arıcılığa dair dört rapor sunulmuştur. Bu kongre arıcılığımızın kalkınması yolundaki en önemli atılım olarak kabul edilmektedir. Özellikle 1951-1952 yılları arasında arıcılığı geliştirmek adına girişimlerde bulunulmuş, Arı Maya Dergisi çıkarılmış ve Türkiye Arıcılık Enstitüsü kurulmuştur. Türkiye Birinci Ulusal Arıcılık Kongresi'nin 1980 yılında gerçekleştirilmesi arıcılık konusuna akademik ilginin son 40 yılda yoğunlaştığını göstermektedir (Sarı̈z, 2006: 40-57; Öter, 2010: 30-31). 


\section{Arıcılık Müzeleri}

Arıcıllk ve bal müzeleri dünyada bal üretiminde öne çıkan ülkeler başta olmak üzere geniş bir coğrafyaya yayılmıştır (Crane, 1999: 613-614; https://www.apiservices.biz) ${ }^{1}$. Balkan ülkelerinde yoğunlaşan Avrupa'daki sayılı müzeler geneli tarihi binalarda hizmet veren, bulundukları coğrafyanın tarihi ve kültürel değerlerini de tanıtan, genellikle arıcılık tarihi, eski ve yeni arıcılık yöntemleri, arıcılıkta kullanılan kıyafetler, araç ve gereçlere yer veren seksiyonlara sahip, bal ve balmumundan yapılmış ürünlerin ziyaretçilere satışının yapıldığı önemli kurumlardır.

Türkiye'de 22.01.1984 tarih ve 18289 sayılı Resmî Gazete' de yayımlanan özel müzeler ve denetimleri hakkında yönetmelik ile özel statüde kurulan Gastronomi müzeleri çerçevesinde arıcllık ve bal müzeleri de gastronomi turizminin konusu olmuştur.

Gastronomi müzeleri konusuyla farklı bir müze çeşidi olarak Gastronomi turizmine yönelik ilginin sonucunda artmış ve süreçte de destinasyonlar için önemli bir Gastronomi turizmi arz kaynağına dönüşmeye başlamıştır (Şengül, 2017: 264-272). Şahin ve Aydın'ın (2017: 184) çalışmalarında yedi adet Zeytin ve Zeytinyağı, dört adet Yöresel Mutfak Kültürü, dört adet Arıcılık, iki adet Şarapçllık, birer adet Mutfak Araç ve Gereçleri, Ekmek Araç ve Gereçleri, Peynircilik, Tıbbi ve Aromatik Bitkiler, Mevlevi Mutfak Kültürü ve Çay Araç Gereçleri olmak üzere toplam 23 adet Gastronomi müzesi listelenmiştir. Bu müzelerden 7'sinin 2001 yılından itibaren, 12'sinin 2010 yılından itibaren kurulması bu arz kaynağına dönüşümün önemli bir göstergesidir. Dört müzenin kuruluş çalışmalarının halen devam ediyor olması Gastronomi müzelerine yönelen ilgiyi kanıtlamaktadır. Gastronomi müzeleri Yılmaz ve Şenel (2014: 501-506) tarafından işlevlerine göre kültürel mirasa dayalı, endüstriyel mirasa dayalı, kırsal turizme dayalı ve popüler kültüre dayalı olmak üzere dört gruba ayrılmaktadır. Bu gruplamaya göre Özel Muğla Arıcılık Müzesi'nin de yer aldığı arıcılık ve bal müzeleri endüstri mirasına dayalı Gastronomi müzeleri içinde değerlendirilmektedir. Bu müzeler "yiyecek ve içecekle ilgili gerek geçmişte kullanılan pişirme kapları, el aletleri, makineler, fabrika ve benzeri unsurları sergileyen, gerekse yiyecek ve içeceklerin tadımına imkân veren keyifli müzeler olarak" nitelendirilmektedir (Yllmaz ve Şenel, 2014: 504).

Türkiye'deki arıcılık ve bal müzelerinden adı balla özdeşleşen kestane balının üretildiği Polonezköy'de Kemal Sayal tarafından arının biyolojisini, balın oluşumunu, balın insanlara ve dünyaya sağladığı faydaları anlatmak amacıyla 2004 yılında açılan Arıcılık Müzesi'nde eskiden ve günümüzde kullanılan arıcılıkla ilgili araç gereçler sergilenmektedir. Müzede çiçek polenleri, arı hücreleri ve peteğin oluşum safhasını gösteren kovanlar bulunmakta, balın nasıl oluştuğu evreleriyle anlatılmaktadır. Bu anlatımlar sergilenen malzemelerin işlevleriyle ilgili kısa bilgilerin yer aldığı bilgi panolarıyla gerçekleştirilmektedir. Saf bal mumu, polen kapanı ve Almanya'dan getirilen ve arıcılıkta kullanılan özel malzemelerin de yer aldığı müzede bal, polen ve arı sütü gibi arıcılık ürünlerinin satışı da yapılmaktadır (http://www.hurriyet.com.tr).

Aydın'daki Adnan Menderes Üniversitesi Çine Arıcılık Müzesi, Çine İlçesi'nin Yağcılar Köyü'nde 4 Ekim 2010 tarihinde, Adnan Menderes Üniversitesi, Çine Belediyesi ve Çine Gelişim Vakfı'nın ortaklığında özel müze statüsünde kurulmuştur. Dünyanın 71. arıcılık müzesi Türkiye'nin ilk arıcilık eğitim müzesi olarak kabul edilen müzede kurslar, seminerler ve farklı eğitimler için 40 kişilik bir eğitim salonu, kafeterya, çocuk parkı, resim atölyesi ve 2000 yıllık

\footnotetext{
1 Önemli Arıcllık Müzeleri için bkz.: Greece Pastida Rhodes Beekeeping Museum - (https://beemuseum.gr), Čebelarski muzej Radovljica - (http://www.radolca.co); Museum of Apiculture (https://www.culture.si), Čebelarski muzej Čebelarstvo Tigeli Krapje - (http://cebelarski-muzej.si), Múzeum včelárstva na Slovensku/ Museum of Beekeeping in Králová pri Senci - (https://www.gob.sk); (Chlebo, 2010: 66), Germany Weimar Beekeeping Museum - (http://dbm.lvti.de), Musée des Arts et Traditions Apicoles - (http://web.tiscali.it).
} 
Roma ve Türk oyunlarının sergilendiği oyun alanı bulunmaktadır (Şengül, 2017:267; http://www.aydinkulturturizm.gov.tr).

Marmaris'in Osmaniye köyündeki Marmaris Bal Evi 2012 yılında hizmete girmiştir. Marmaris Ticaret Odası Başkanlığı tarafından açlan ve işletilmekte olan müzede geçmişten günümüze balın üretimi ile ilgili bilgiler verilmekte, bal ve baldan üretilenlerin tadımı yapılmakta, bal ile ilgili araç ve gereçler sergilenmektedir. Ayrıca eğitim birimi, müze bölümü, sunum odaları, küçük teşhir amaçlı bir dolum alanı ve satış birimi yer almaktadır (Bekâr, Arman ve Sürücü, 2017: 471-472; www.marmarisbalevi,com.tr). Müzedeki odak noktalarından biri de köy kadınlarının hem özgün ve otantik yerel ürünlerini sergileyebildikleri hem de eğitim alabildikleri atölye ve toplantı salonlarıdır (Kara vd., 2017:421).

Paylaşımlarından 2007 yılında oluşturulduğu anlaşılan Sanal Arıcılık Müzesi dünden bugüne arıcılıkta kullanılan araç ve gereçleri, Osmanlı ve Cumhuriyet dönemine ait arıcılık ve arılar üzerine yazılan kitapları açıklamaları olmaksızın temel bilgileriyle tanıtmakta, Arıcılık Müzeleri'nin internet sayfalarının adreslerini de vermektedir (www.aricilikmuzesi.blogspot.com).

\section{YÖNTEM}

Araştırmada nitel veri elde etme tekniği olan görüşme yöntemi ile gözlem tekniği kullanılmıştır. Çalışmanın başlangıcında önce Özel Muğla Arıcılık Müzesi ziyaret edildikten ve müze yönetiminden bilimsel çalışma izni alındıktan sonra sırasıyla Marmaris Bal Evi Müzesi, Özel Muğla Arıcılık Müzesi, Adnan Menderes Üniversitesi Çine Arıcılık Müzesi ve Yazla Arı Çiftliği her iki araştırmacı tarafından ziyaret edilerek iki saat ile birer gün arasında süren incelemelerde bulunulmuş, kayıtlar tutulmuş ve fotoğraflar çekilmiştir. Daha sonra ilgili literatür incelenerek dokuz sorudan oluşan yarı yapılandırılmış görüşme formu hazırlanmıştır. Görüşme formunda yer alan sorular aşağıdaki gibi sıralanmıştır:

1. Sakıncası yoksa yaşınızı söyler misiniz?

2. Kurumdaki pozisyonuz nedir?

3. Kaç yıldır bu pozisyonda çalışmaktasınız?

4. Müzenizde kaç çalışan bulunmaktadır?

5. Müzeniz ne zaman özel müze statüsünde hizmet vermeye başlamıştır?

6. Müzede hangi bölümler bulunmaktadır?

7. Müzeyi ziyaret edenlerle ilgili bilgiler nelerdir?

8. Müzenin bir broşürü var mıdır? Düzenlenen şenlik, festival vb. ne gibi gastronomik faaliyetler gerçekleştirilmektedir?

9. Muğla'da arıcılık kültürel, gastronomik ve turistik olarak daha iyi nasıl değerlendirilebilir?

Dört müze yöneticisi, bir arı çiftliği yöneticisi ile yüz yüze görüşmeler gerçekleştirilmiştir. OcakMart 2019 tarihlerinde gerçekleştirilen görüşmelerde ses kayıtları tutulmuş ve aynı zamanda notlar alınmıştır. Görüşmeler 50 dakika ile 90 dakika arasında sürmüştür. Muğla Özel Arıcılık Müzesi'nin taşınması ve belediye ile ilgili hususların araştırılması için iki Muğla Büyükşehir Belediyesi yetkilisi ile ayrıca görüşme gerçekleştirilmiştir. Görüşme iki saat sürmüştür. Araştırma sonucunda elde edilen veriler yazıya dökülerek birer nihai düz metin haline getirilmiştir. 


\section{BULGULAR ve TARTIŞMA}

\section{Araştırmaya Katılanlara İlişkin Bulgular}

Katılımcıların cinsiyeti, yaşı, çalıştı̆̆ı pozisyonu, iş deneyimi ve bulundukları ilçe bilgileri Tablo 1 'de gösterilmiştir. Katılımcıların \%28,57'si kadın ve \%71,43'ü erkek ve yükseköğretim düzeyinde eğitim sahibidirler. Katılımcıların ifadelerine metin içinde yer verilirken K1, K2...K7 şeklindeki kodlar kullanılmıştır.

\section{Tablo 1. Katılımcı Yetkililer}

\begin{tabular}{llllll}
\hline Katılımclar & Cinsiyet & Yaş & Pozisyon & Deneyim & Ilçe \\
\hline K1 & Kadın & 50 & Ziraat Mühendisi & 5 & Menteşe \\
K2 & Erkek & 36 & Gıda mühendisi & 9 & Menteşe \\
K3 & Erkek & 37 & Müze Yöneticisi & 10 & Marmaris \\
K4 & Erkek & 50 & Arı Çiftliği Sahibi & 8 & Akyaka \\
K5 & Kadın & 33 & Gida Mühendisi & 18 & Menteşe \\
K6 & Erkek & 40 & Ziraat Mühendisi & 20 & Menteşe \\
K7 & Erkek & 37 & Müze Yöneticisi & Çine \\
\hline
\end{tabular}

\section{Muğla'da Arıcılık}

Antik kaynaklarla, epigrafik ve arkeolojik verilerden Bodrum yakınlarında Theangela, Milas ile Bafa Gölü arasında Pedasa, Milas, Kafaca köyünde lokalizasyonu yapılan Olymos ve Knidos kentlerinde, ayrıca bölgenin Ege denizindeki sınırları içinde yer alan Kalymnos ve Rhodos adalarında arıcılık yapıldığı, yüksek kalitede bal üretildiği ve bu balın bölgenin en önemli ihraç ürünlerinden biri olduğu özellikle de Misır'a gönderildiği anlaşılmaktadır (Sevin, 2001:131; Magie, 2002: 36-116; Lenger, 2011:28-35). Mısır'a ihraç edilen sadece bal değildir, arıcılık Ptolemaioslar döneminde yeniden organize edilirken özellikle Karia'dan gelen arıcıların üretim metotları da kullanılmaya başlanmıştır (Lenger, 2011:31).

Coğrafi olarak batıda ve güneyde Ege Denizi'yle, kuzeyde Büyük Menderes (Maiandros), doğuda Kızılhisar-Acıpayam Ovası ile sınırlı, günümüz Muğla ilinin de yer aldığı Karia bölgesi balları, Antik dönemin en iyi balları arasında ikinci sıradadır ve bölgede arıcılık önemli bir iş kolu olarak kabul edilmektedir (Aksan, 2007:2-3).

Muğla'da arıcılı̆̆ın Osmanlı döneminde önemli bir geçim kaynağı olduğu Devlet arşivindeki 16.yüzyıla ait belgelerden anlaşılmaktadır. 1909 yılından itibaren arıcılık kentte gelişen bir sektör haline gelmiş, Türkiye'de ilk arıcılık ve bal kooperatifi de 1951 yılında Muğla' da kurulmuştur. Arı varlığı, bal üretimi ve arıcı sayısı ile ülkemizde ilk sıralarda yer alan Muğla'nın ekonomisinin yanı sıra kültüründeki en önemli geleneksel üretimlerden biri de arıcılıktır. Muğla'da arıcılık, turizm gibi kentin 1980'lerden sonra öne çıkan faaliyetlerindendir. Kentte arıcılık ve bal üretimi çam ormanları sayesinde yapılmaktadır. Gezgin arıcılar diğer bal türlerinin de Muğla'da üretilmesini sağlamaktadır. Buna rağmen Türkiye'nin ihraç ettiği balın tamamına yakın bölümü çam balıdır ve ihraç edilen balın \% 80'i çam balı merkezi olan Muğla'da üretilmektedir. Türkiye' nin toplam kovan sayısı TÜIK verilerine göre 2017 yılında 8 milyona yakındır. Toplamda 958000 kovana sahip olan Muğla, yaklaşık \%12 oranı ile birinci sırada bulunmaktadır. Bu bilgi kentin günümüzde de Antik dönemdeki yoğunlukta ihracatta söz sahibi olduğunu göstermektedir (www.tuik.gov.tr; Suna, 2018: 47; Çukur, Dayan ve Karabulut, 2010: 26; Öter, 2010: 32; Öztürk ve Şahin, 2008:65-66).

Muğla'da arıcılık konusunda katılımcıların görüşleri ise şöyledir; Arı Muğla'nın en önemli unsurlarından biridir. Yerel ürün olarak tanıtımının yapılması gerekir (K1 ve K4). Muğla'ya her yıl 3 milyon civarında kovan gelmekte ve 5000 civarında arıcı bulunmaktadır. Muğla'nın iki önemli ürünü turizm ve arıcllktır ve bu bir avantajdır. Gereken önemin daha fazla verilmesi gerekir (K1). Biz bir taraftan 
arıcılı ile uğraşırken diğer taraftan da arı ürünlerinden hediyelik eşyalar üretmekteyiz. Buradaki çiftlik dışında da satışlarımız yapılmaktadır (K4).

Arının Muğla'nın çeşitli yerlerine heykelleri yapılabilir (K1 ve K2). Ancak, İzmir'e giden yoldan (Menteşe Blokları) başlayarak Denizli kavşă̆ına kadar ki kavşaklarda belediye heykeller yaptırma girişiminde bulundu. Karayolları görüşü engellediği için kavşaklarda arı heykellerinin bulunmasına izin vermedi. Muğla-İzmir çıkışında kavşak öncesi Muğla'ya giriş tabelasının olduğu yerde Belediyeye ait istinat duvarına arı rölyefi yapılabilecektir (K5 ve K6).

\section{Özel Muğla Arıcılık Müzesi}

Muğla İli Arı Yetiştiricileri Birliği (MAYBİR) tarafından Özel Muğla Arıcılık Müzesi, Muğla arıcılığını ve dünyaca ünlü çam balını öne çıkarmak temel hedefiyle hem Muğla arıcılığının hem de ülkemiz arıcıllğının tarihsel sürecini yansıtmak, kentin somut olmayan kültürel miras değerlerinden biri olan arıcılık kültürünü tanıtmak ve ülkemiz kültür turizmine hizmet etmek amaciyla kurulmuştur.

Muğla Özel Arıcllı Müzesi'nin kuruluş dayanağı, 863 sayılı Kültür ve Tabiat Varlıkların Koruma Kanunu'nun 26. maddesidir ve 5 Ekim 2010 tarihinde özel müze statüsüne kavuşmuştur. T.C. Kültür ve Turizm Bakanlı̆̆ı'nın 16.08.2012 tarih ve 182225 sayıl makam olurundan sonra, Muğla İl Kültür ve Turizm Müdürlüğü'nün 29.08.2012 tarih ve 6402 sayıl yazısı ile izin işlemleri tamamlanmıştır. Müze 2012 yılından itibaren Kültür ve Turizm Bakanlı̆̆ı'ndan ruhsatl özel müze olarak faaliyetlerini sürdürmektedir (K1 ve K2).

MAYBİR binasının giriş katı müze olarak düzenlenmiştir. Girişinin iki yanında arı heykelleri ve insan heykeliyle anlatımı güçlendirilen bir arı bahçesi yer almaktadır. İç mekânda girişin sağında geleneksel kıyafetleriyle kadın ve erkek heykeli ile satış bölümü bulunmaktadır. Müze sergilemesi iki bölümden oluşan $U$ formunda düzenlenmiştir. Arka bölümde girişin sağından başlayarak sola doğru; vitrin içinde arıcılıkla ilgili kitaplar ve bal mumu eserler sergilenmektedir. Vitrin sonrasında farklı formlarda kovanlar, bal küpleri, kovan yapımı ve kovan demirleri, oğsak, arıcıların yaşamı, kovan taşımacılığı ve bu taşımacılıkta kullanılan nakil araçları, konaklama üniteleri çadır ve baraka, arıcının bal yolculuğunu anlatan aletler, maketler ve heykeller yer almaktadır. Ön bölümde ise yine sağdan sola doğru arı süpürme aletleri, bal hasadı için küçük el aletleri, doğal arı yuvaları ahşaptan destekler üzerinde yer alan altıgen arı kovanı formundaki vitrinlerde sergilenmektedir. Bu bölümün ortasında kütük kovanlarda bal kesimi, arı bakımları, mum sıkma petek ve petek basımı alet, maket ve heykellerle sergilenmektedir. Sol bölümde ise yine ahşap destek üzerindeki arı kovanı formlu vitrinler içinde aydınlatma aletleri, eski ve yeni körükler yer almaktadır. Petek formlu vitrinler arasında ise yöredeki arıcıkla ilgili 16.yüzyıla ait belgeler Osmanlıca özgün ve Türkçe açıklamalarıyla sergilenmektedir. Müze duvarlarında ise çeşitli sanatçıların farklı teknik ve formda arı ve bal konulu eserleri bulunmaktadır. Muğla'daki müze her yıl 3.000'i aşkın kişi tarafından ziyaret edilmektedir (K1). Sinevizyon gösterimiyle arının bal yolculuğu 50 dakikalık bir belgeselle anlatılmakta, tüketicilere doğru bal üretiminin nasıl yapıldığı gösterilerek organik bal konusunda bilgilendirme yapılmaktadır (https://www.maybir.org.tr).

\section{SONUÇ ve ÖNERILER}

Türkiye'nin en önemli bal üretim merkezi Muğla'da arıcıllı̆ın geliştirilmesi, turizm ve sağlık sektörleriyle birlikte nasıl bütünleşebileceği ile Türkiye'deki sayılı Gastronomi müzelerinden ve 
Arıcllık müzelerinden biri olan Özel Muğla Arıcılık Müzesi'nin daha iyi bir konuma getirilebilmesi amaçlı öneriler aşağıdaki şekilde sıralanmıştır.

\section{Muğla'da Arıcılık ve Turizme Yönelik Öneriler}

Yapılan araştırmalar Avrupa Birliği ülkelerinin damak zevkine en uygun balın çam balı olduğunu göstermektedir (www.geka.gov.tr). Muğla'nın arıcılıkta Türkiye'nin merkezi olduğu, dünya çam balı üretiminde önemli bir konumda olduğu gerçeğinden yola çıkılarak çam balına sahip çıkmak, onu tanıtmak ve çam balını uluslararası bir marka olarak turizme kazandırmak, arıcılık faaliyetlerinin gelişimi ve ürünlerin turizm aracılığıyla pazarlanması için en küçük yerel birim muhtarlıklardan başlayarak kentteki bal birlikleri, ilgili Bakanlık birimleri ve tarım müdürlükleri, turizm alanındaki birlik, dernek ve işletmelerle, turizm işletmeleri işbirliği yaparak üzerlerine düşen görevleri yerine getirmelidirler (Öter, 2010:35-36). Bu amaçla arıcılık ürünleri güçlü markalarla piyasaya sunulmalıdır.

Muğla'da birbirini tamamlayan iki sektör arıcılık ve turizmdir (K1ve K4). Turizm açısından ekonomik ve turistik çekiciliğe sahip arıcılık ürünlerinin pazarlanmasında aracıların varlığı sorun oluşturmaktadır. Bu nedenle pazarlama konusunda aracıların yer almadığı sadece ilgili kişilerin muhataplığında bir düzen oluşturulmalıdır.

Bölgenin ballarının detaylı tanıtılması hedeflenerek, Türkçe ve İngilizce olarak bilimsel nitelikte broşür, kitap, film, belgesel ve diğer tanıtım materyalleri hazırlanmalı, çam balını tanıtmak amacıyla yurt içi ve dışındaki turizm, organik gıda ve arıcılık fuarlarına gidilmelidir. Bu anlamda MAYBİR'in 2008 yılından itibaren düzenli olarak çam balının uluslararası tanınırlı̆̆ını artırmak amacıyla iki yılda bir gerçekleştirdiği "Uluslararası Muğla Arıcılık ve Çam Balı Kongresi" önemlidir. Bu tarz kongre, seminer ve toplantıların ulusal ve uluslararası düzeyde gerçekleştirilmesine devam edilmelidir.

Slovenya'da arıcılığın öncülüğünü yapan arıcılık okulunun müdürü ve arıcılık üzerine çok sayıda kitabı bulunan bilim adamı Anton Jansa'nın doğum tarihi olan 20 Mayıs, 20 Aralık 2017 tarihinde Birleşmiş Milletler Genel Kurulu'nda oybirliğiyle Dünya Arı Günü olarak kabul edilmiştir. 20 Mayıs arıcılık ve bal ile ilgili etkinliklerin Muğla' da yoğun olarak yapıldığı bir gün olarak değerlendirilmelidir.

Diğer ballardan ayırt edici özelliklerinin belirlendiği bilimsel çalışmalara bakıldığında Muğla Çam Balı'nın tescil edilmesi gereği ortaya çıkmış, Çam Balı adı Muğla ile özdeşleşmiştir (Şahin, 2016). Muğla Çam Balı Coğrafi İşaret tescil başvurusu, 15.08.2018 tarihinde Türk Patent ve Marka Kurumu tarafindan onaylanarak tescil edilmiştir (K1 ve K2). Tanitımlarda tescil konusunun ön planda tutulması avantajlar sağlayacaktır.

Her türlü arıcılık potansiyeline sahip Muğla'da araştırma enstitüsünün olmaması büyük bir eksikliktir. 70'li yıllarda Fethiye'de Türkiye'nin ilk ana arı üreten kurumu Arıcılık Üretme İstasyonu açılmış, ancak 2003 yılında kapatılmıştır (http://www.gazetesah.com). Muğlalı arıcıların beklentisi yerine getirilerek kapatılan Arıcılık Üretme İstasyonu, Arıcılık Araştırma İstasyonu'na dönüştürülmelidir.

Geleneksel arıcılık deneyiminin ve ürün çeşitliliğinin, ekonomik kalkınmayı sağlayacak biçimde nasıl yeniden ele alınabileceği temel sorusuna cevap arayan atölye yeni etkinlikler gerçekleştirilmelidir.

2017 yılında hayata geçirilen Marmaris Çam Balı Şenliği ve kapsamındaki "Ballı Yemekler" atölye çalışması, Marmaris Orhaniye köyünde geleneksel hale getirilen Bal ve Kültür Festivali, düzenli olarak her yıl yapılan Köyceğiz Bal Festivali, ilki 2011 yılında gerçekleştirilen ancak bir 
daha yapılmadığı anlaşılan 1. Ula Çam Balı Festivali, 2017 yılında ilki gerçekleştirilen Akyaka Susam ve Çam Balı Şenliği gibi bal odaklı çevre ilçelerde yapılan ya da yapılmakta olan festival ve şenliklerin gastronomi ve kültür şenlikleri kapsamında Muğla merkezdeki benzerleriyle birleştirilerek daha büyük organizasyonlar yapılabilir. Mevcut bal kalitesini belirleyen yarışmaların da devamı önemlidir.

\section{Muğla'da Arıcılık ve Apiturizme Yönelik Öneriler}

Muğla'da Arıcllk ve Gastronomi Turizmi konusunda ilgili kurum ve kuruluşlar projeler üretmeli, üreticilere arıcılık konusunda yenilenen bilgiler verilmelidir (K1 ve K4). Yapılan araştırmalarda genç neslin arıcılığa ilgi göstermemesi nedeniyle arıcı sayısının azaldığı vurgulanmaktadır (Öztürk, 2017: 56-57; Çukur, 2014: 45-46; www.geka.gov.tr; Tuna 2016: 234). Arıcılık mesleğinin cazip hale getirilmesi için mevcut üretim koşullarının iyileştirilmesi, arıcılık kredilerinin artırılması ve bu konuda teknik destek verilmesi gerekmektedir.

Muğla'da arıcılık, sağlık turizminde özellikle apiterapi (arıların tedavi amaçlı kullanımı) alanında da yaygin olarak kullanilabilir (K1ve K4; Öter, 2010:35-36; Bahar ve Y1lmaz, 2016: 537). Bu amaçla hükümet ve yerel yönetimler bir araya gelmeli, otel ve diğer işletmeler yerine, destinasyon veya bölge bazında turizm konsepti geliştirilmelidir. Bu çerçevede içinde kovan formlu evlerin yer aldığı, gelen ziyaretçilere farklı aktivitelerin sunulduğu arı rotaları oluşturulmalıdır. Burada çalışanlara gerekli eğitim verilerek yurt dışındaki merkezlerde tecrübe edinmeleri sağlanmalıdır. Böylece Muğla bir apiterapi destinasyonu olarak uluslararası pazarlara tanıtılabilmelidir.

28 Nisan 2017 tarihinde Muğla İl Gıda Tarım ve Hayvancılık Müdürlüğü tarafından hazırlanan "Apiterapi Ürünleri Muğla'da Üretilir" başlıklı proje gerçekleştirilmiştir (http://www.muglakentgazetesi.com). Muğla'nın dünyadaki apiturizm merkezlerinden biri haline getirilmesi için bu tür projeler devam ettirilmelidir.

Kentte çok az üretilen apiterapi ürünlerinden arı sütü, propolis, polen üretiminde artış sağlanmış, özellikle kozmetik sektöründe bu ürünlerden yararlanmaya başlanmıştır (K4). Yerel bir arı çiftliğinde Türkiye'de ilk defa değişik bir konsept olarak tanıtılan cilt bakım bölümü kurulmuş, bu bölümde balmumu ve arı sütlü el ve yüz bakım ürünleri, saç bakım maskesi, dudak stiki, güneş kremi, propolisli gece bakım serumu gibi birçok faydalı ürünlerle, propolisli sinek kov satışa sunulmuştur. Bu üretim çeşitlemesinin yaygınlaşması ve oluşturulan api rotalarında pazarlanması gerekmektedir.

\section{Özel Muğla Arıcılık Müzesi'nde Olması Gerekenlere Yönelik Öneriler}

Müzede arıcılık alanında uzman kişiler çalışmaktadır. Bunun yanı sıra bir müzeolog ve eğitimcinin de müze kadrosunda yer alması gerekmektedir.

Kalıcı seksiyonlardan biri Arıcılık Tarihi temasını içermelidir. Bu bölüm insanın bütün duyularına hitap edebilecek teknik donanıma sahip olmalıdır.

Müzede yeni teknolojiler daha fazla kullanılmalıdır. Bu bağlamda bilgisayar destekli sergileme, dokunmatik ve interaktif sistem, simülatör, sanal müzecilik, mobil telefon uygulamaları araştırılmalıdır (Kervankıran, 2014: 364).

Müzeler, nesnenin kendisiyle eğitim ve öğretim gerçekleştirdiği için "en güçlü eğitim kurumlarıdır" (Çevik, 2010: 13). Arıcılık ve bal ile ilgili etkili farkındalık yaratmak için okullarda daha çok tanıtım yapılmalıdır. Bu kapsamda Muğla ve ilçelerindeki okullarda eğitim gören çocukların müzeyi ziyaret etmeleri sağlanmalıdır. 
Yaşayan müze olarak çocukları ve gençleri cezbedecek açık hava sergilemelerine öncelik verilmelidir.

Müzede bir çocuk bölümü yer almalıdır. Burada çocuklar için arıcılık ve bal ile ilgili kostümlere, boyama yapabilecekleri materyallere, yapbozlara yer verilmelidir.

Bal ve bal ürünlerinin yanı sıra balla yapılan geleneksel, apiterapi ve kozmetik ürünlerin pazarlaması sağlanarak müze kafeteryasında satışa sunulmalıdır.

Çevrimiçi konumlandırmayı iyileştirmek için araçlar geliştirilmeli; bloglara, sosyal medyalara, arama motorlarına, reklamlara önem verilmeli (WTO, 2019: 41), müzenin internet sayfası yenilenmeli ve iki veya çok dilli olarak hizmet vermelidir.

Mevcutta Türkçe bir kitapçık olmasına rağmen arı ve bal hakkında kısa bilgiler içeren müzeye özgü farklı dillerde broşür/kitapçık hazırlanmalıdır.

Müzenin yurt dışında bir kardeş müzeye sahip olması ve böylece uluslararası düzeyde iş birliği yapılarak ortak etkinlikler düzenlenmesi sağlanmalıdır.

Seyahat acentaları kent merkezinin tarihi ve kültürel değerlerinin tanıtıldığg turlar kapsamında yerli ve yabancı turistlerin müzeyi ziyaret etmelerini sağlamalıdır. Marmaris'teki müzeyi her yıl 40.000'den fazla kişi ziyaret ederken (K3), Çine Arıcllk Müzesi'ni ziyaret edenlerin daha çok çevre okullardan gelen öğrencilerin olduğu ve yıllık ziyaretçi sayısının 600 civarında kaldığı tespit edilmiştir (K7). Özel Muğla Arıcllk Müzesi ise 3000 kişi tarafından ziyaret edilmektedir (K1 ve K2). Müzenin yerinin değiştirilmesi, yapılacak yeni düzenlemeler ve görevlendirmeler sayesinde ziyaretçi sayının çok daha yükseltilebilmesi mümkün olacaktır.

Farklı ziyaretçilerin müzeye gelmeleri için müzede sergiler, film gösterimleri, söyleşiler gibi etkinlikler arttırılmalıdır.

Müzeler Haftası'nda müzede çocuklara ve yetişkin ziyaretçilere ayrı etkinlikler hazırlanmalıdır.

Müzede bir uygulama mutfağına yer verilmelidir. Burada ziyaretçilerin ballı yiyecek ve içecek yapmalarına olanak sağlanmalıdır.

Müzenin yerinin değiştirilmesi bu çalışmada önemli bir öneri olarak sunulmaktadır (K1, K2, K5 ve K6). MAYBİR binasının giriş katında yer alan müze ayrı bir binaya sahip olmalıdır. Ulaşılması kolay, park imkânı ve büyük bir bahçesi olan altıgenler, yani arı kovanı formunda mimari tasarıma sahip bir müze binasının yapılması sağlanmalıdır. Yeni binada ziyaretçilerin uygulama yapabilecekleri bir mutfak, çocuk bölümü, sergi salonları, laboratuvar, konferans salonu, kafeterya ve satış bölümü yer almalıdır.

\section{KAYNAKÇA}

Aksan, M. (2007). Karia Bölgesi Arkeolojisi Üzerine Bir Değerlendirme, 1-10. İçinde: Özden, S. ve Aksan, M. (Ed.), TAY - Türkiye Arkeolojik Yerleşmeleri-7: Yunan-Roma Dönemi / Pisidia ve Karia Bölgeleri. Ege Yayınları: İstanbul.

Albayrak, İ. (2002). Kültepe'den Değişik Bir Masraf Listesi, Archivum Anatolicum, 5, 1-10.

Anagnostakis, I. (2013). Byzantine Delicacies, 81-104. In: Anagnostakis, I. (Ed.), Flovoursand Delights Tastesand Pleasures of Ancient and Byzantine Cuisine. Armos, Athens.

Bahar, O. ve Yılmaz, E. (2016). Arı Turizmi ve Muğla'da Uygulanabilirliği, 5. Uluslararası Muğla Arıcilı ve Çam Balı Kongresi Raporu,1-5 Kasım. Fethiye, Muğla. 
Bekâr, A., Arman, M. S. ve Sürücü, Ç. (2017). Turizmde Çekicilik Unsuru Olarak Gastronomi Müzeleri: Marmaris Bal Evi Örneği. Akademik Sosyal Araştırmalar Dergisi, 42, 468-477.

Brown, R. (1993). Bee Hive Product Bible. Wondrous Products from One of Nature's Most Productive Creatures. CC Pollen Company: USA.

Bulut, S. (2010). Tarih ve Arkeolojide Arıcılık, 21-25. İçinde: Çevik, N. ve Kösoğlu, M. (Ed.) Çine Arıcılık Müzesi Çalıştay ve Panel Bildirileri, Çine Belediyesi: Aydın.

Bulut, S. (2015). Lykia'da Arıcılık, Seren ve Çevre Duvarlı Arılıklar Işığında Antik Geleneği Arayış, 97-132. İçinde: İşkan, H. ve Işık, F. Kumdan Kente Patara Kazılarının 25. Yılı Uluslararası Sempozyum Bildirileri, Oksijen Basım: Bağcılar, İstanbul.

Bulut, S. (2016). Eski Akdenizde Arı Ürünleri, 166-177. İçinde: Dündar, E., Aktaş, Ş. vd., (Ed.), Havva İskan'a Armağan, LYKIARKHISSA Festschriftfür Havva İşkan. Ege Yay. İstanbul.

Bulut, S. ve Lenger, D. S. (2015). Antik Dönemde Arı Ürünlerinin Kullanımı, 7-16. İçinde: Akçiçek, E. ve Yücel, B. (Ed.), Arı Ürünleri ve Sağllk (Apiterapi). Sidas Medya: İzmir.

Chlebo, R. (2010). Changes in Slovakian Beekeeping, Bee World. 12, 66-70.

Crane, E. (1999). The World History of Beekeeping and Honey Hunting, New York: Routledge.

Çevik, N. (2010). Akdeniz Üniversitesi VI. Müzecilik Çalıştayı ve Paneli “Adnan Menderes Üniversitesi Çine Arıcılık Müzesi Üzerine Bazı Notlar", 10-16. İçinde: Çevik, N. ve Kösoğlu, M. (Ed.) Çine Arıcıllk Müzesi Çalıstay ve Panel Bildirileri. Çine Belediyesi: Aydın.

Çukur, F. (2014). Muğla İli Milas İlçesinde Arıcılık Faaliyetinin Sürdürülebilirliliğgi Üzerine Bir Değerlendirme, 40-47. İçinde: Ceyhan, V. vd. (Ed.). XI. Ulusal Tarım Ekonomisi Kongresi, (Cilt-I), 35 Eylül: Samsun.

Çukur, T., Dayan, V. ve Karabulut, A. N. (2010). Muğla İlinde Sürdürülebilir Arıcılık, 18-27. İçinde: Öztürk, A. İ. (Ed.), 2. Uluslararası Muğla Arıcılık ve Çam Balı Kongresi Kitabı, 5-8 Ekim: Muğla.

Curtis, R. I. (2001). Ancient food technology, Brill: Lieden, Boston.

Dalby, A. (2003). Food in the ancient world from A to Z, Routledge: London, UK; New York, USA.

Dalby, A. (2004). Bizans'ın Damak Tadı, Kokular, Şaraplar, Yemekler, Kitap Yayınevi: İstanbul.

Doğer, L., ve Armağan, E. (2014). Bizans Döneminde Prousa (Bursa) ve Çevresinde Gündelik Beslenme Üzerine Bir Deneme, Sanat Tarihi Dergisi, 23(2), 13-48.

Erkut, S. (2011). Hititler'de Arı ve Bal, ActaTurcica, 1(1), 36-39.

geka.gov.tr/Dosyalar/ o_19v5fo8p79mr1mps1r 751qp38148.pdf, Muğla İli Tarım ve Hayvancllı Çalıştay, Güney Ege Kalkınma Ajansı (GEKA), MiTHÇ Sonuç Raporu, (2013). [Erişim Tarihi: 12.12.2018].

Germanidou, S. (2018). Honeyculture in Byzantium: an outline of textual, iconographic and archaeological evidence, 93-104. In: Hatjina, F., Mavrofridis, G., and Jones, R. (Ed.) Beekeeping in the Mediterranean from antiquity to the present, Nea Moudania, Greece.

Graf, F. (1980). Milch, Honig und Wein: Zum Verständnis der Libation im griechischen Ritual, 209-221. In: Piccaluga, G. (Ed.), Perennitas. Studi in onoredi Angelo Brelich, Edizionidell' Ateneo: Rome. 
Harissis, H. V. (2017). Beekeeping in prehistoric Greece, 18-39. In: Hatjina, F., Mavrofridis, G., and Jones, R. (Ed.), Beekeeping in the Mediterranean from antiquity to the present, Nea Moudania, Greece.

http://www.aricilikmuzesi.blogspot.com [Erişim Tarihi: 16.06.2018].

http://cebelarski-muzej.si/tigeli/de/ bienenmuseum [Retrieved Date: 02.07.2018].

http://dbm.lvti.de, Deutsches Bienenmuseum Weimar. [Retrieved Date: 22.06.2018].

http://web.tiscali.it/ aaab_it/causega.htm, Museedes Arts Et Traditions Apicoles. [Retrieved Date: 27.06.2018].

http://www.aydinkulturturizm.gov.tr/TR,64421/cine-aricilik-muzesi.html [Erişim Tarihi: 12.12.2018].

http://www.gazetesah.com/ aricilik-arastirma-istasyonu-talebi/ Arıcılık Araştırma İstasyonu Talebi (2013 tarihli haber), [Erişim Tarihi: 22.12.2018].

http://www.hurriyet.com.tr/ kelebek/turkiye-nin-tek-ari-muzesi-4910316, Türkiye'nin Tek Arl Müzesi (2006 tarihli haber), [Erişim Tarihi: 12.12.2018].

http://www.marmarisbalevi.com.tr/tr/ marmaris-bal-evi-hakkinda, Marmaris Bal Evi. [Erişim Tarihi: 16.12.2018].

http://www.muglakentgazetesi.com/apiterapi-urunleri-egitimine-buyuk-ilgi, Apiterapi Ürünleri Eğitimine Büyük İlgi, (28.04.2017 tarihli haber). [Erişim Tarihi: 26.12.2018].

http://www.muglakulturturizm.gov.tr/TR,73684/bal-ve-aricilik-kulturu.html [Erişim Tarihi: 12.12.2018].

http://www.radolca.com/de/ imkereimuseum-radovljica/ [Retrieved Date: 27.06.2018].

https://beemuseum.gr/museum/ [Retrieved Date: 16.06.2018].

https://www.apiservices.biz/fr/bases-de-donnees/musees-apicoles, Apiservices. Bee Museums Muséesapicoles - Apiculturamuseos - Imkereimuseen, [Retrieved Date: 27.06.2018].

https://www.culture.si/en/ Museum_of_Apiculture, Radovljica [Retrieved Date: 27.06.2018].

https://www.gob.sk/poi/5112/ museum-of-beekeeping [Retrieved Date: 13.06.2018].

Kahyaoğlu, M. (2011). Hanedan Sembolü Olarak Arı. Bee as a Regal Symbol, Acta Turcica, 1(1), 102-108.

Kara, E., Bingöl, Z., Karadağ, L. ve Baysal, K. (2017). Gastronomi Turizmi Çerçevesinde Yöresel Ürünlerin Turizme Kazandırılması: Marmaris Bal Evi Örneği, 413-426, İçinde: Avcıkurt, C. vd., (Ed.) Gastronomi Üzerine Araştırmalar, Detay Yay. Ankara.

Kervankiran, İ. (2014). Dünyada Değişen Müze Algısı Ekseninde Türkiye'deki Müze Turizmine Bakıs, Turkish Studies-International Periodical for The Languages, Literature and History of Turkishor Turkic, 9(11), 345-369.

Lenger, D. S. (2010). Antikçăg'da Bal ve Beslenme, Arkeoloji ve Sanat, 134, 89-96.

Lenger, D. S. (2011). Antik Çağda Karia Bölgesinde Bal, Honey in the Karia Region in Antiquity, Acta Turcica 1(1), 28-35.

Magie, D. (2002). Anadolu'da Romalılar 2: Batı Anadolu ve Zenginlikleri, Çeviri: Başgelen, N. ve Çapar, Ö. Arkeoloji ve Sanat Yayınları: İstanbul.

Mellaart, J. (2003). Çatalhöyük Anadolu'da Bir Neolitik Kent, Yapı Kredi Yayınları: İstanbul. 
Öter, Z. (2010). Özgün Yerel Ürünlerin Uluslararası Ziyaretçilere Pazarlanması: Muğla'da Arıcılık ve Turizm Örneği, 28-37. İçinde: Öztürk, A. İ. (Ed.), 2. Uluslararası Muğla Arıcılık ve Çam Balı Kongresi Kitabı, 5-8 Ekim: Muğla.

Öztürk, A. İ. (2017). Muğla İli Ula İlçesi Arıcılığının Bazı Teknik Özelliklerinin Belirlenmesi, Hayvansal Üretim, 58(2), 52-57.

Öztürk, A. İ. ve Şahin, Z. (2008). Muğla Arıcılığının Ekonomik Önemi, 64-66. İçinde: Öztürk, A. İ. ve Doğaroğlu, M. (Ed.), 1. Uluslararası Muğla Arıcılık ve Çam Balı Kongresi. 25-27 Kasım: Muğla.

Sariöz, P. (2006). Arı Biziz, Bal Bizdedir. Dünden Bugüne Türkiye'de Arıcılı, Balparmak Yayınları: İstanbul.

Sevin, V. (2001). Anadolu'nun Tarihi Coğrafyası I, Türk Tarih Kurumu Yayınları: Ankara.

Suna, B. (2018). Api Turizm'in Türkiye'deki Yeri ve Önemi. Uludağ Arıcllk Dergisi, 18(1), 42-51.

Şahin, Ö., and Aydın, A. (2017). A Cultural, Gastronomic, and Touristic Asset: The Kuşadası Oleatrium Olive and Olive Oil History Museum Case, Journal of Tourism and Gastronomy Studies, 5(4), 180-199.

Şahin, Z. (2016). PPT Sunum, 5. Uluslararası Muğla Arıcılık ve Çam Balı Kongresi 1-5 Kasım, Fethiye, Muğla. http://yucita.org/ uploads/ ulusaletkinlik/2016_1/Ziya_Sahin-Muglada_Dunden _Bugune_Cam_Bali.pdf [Erişim Tarihi: 22.12.2018].

Şahinler, N. (2000). Arı Ürünleri ve İnsan Sağlığı Açısından Önemi, MKÜ Ziraat Fakültesi Dergisi, 5(1-2): 139-148.

Şengül, S. (2017). Turizm Arz Kaynağı Olarak Gastronomi Müzeleri (Türkiye Örneği), 262-274. İçinde: Bozok, D. vd. (Ed.), Gastronomi Üzerine Araştırmalar, Detay Yay. Ankara.

Tekin, O. (1992). Antik Numismatik ve Anadolu (Arkaik ve Klasik Çağlar), Arkeoloji ve Sanat Yayınları: İstanbul.

Tuna, M. (2016). Muğla İlinin Kırsal Kalkınma Potansiyelinin Belirlenmesi Projesi, GEKA Proje Raporu.

Ulusoy, E. (2012). Bal ve Apiterapi. Uludă̆ Arıcllk Dergisi, 12(3), 89-97.

Üreten, H. (2011). Eski Anadolu'da Arı ve Bal. History Studies, 3(3), 363-382.

Woś, B. (2014). Api-tourism in Europe, Journal of Environmental and Tourism Analyses, 2(1), 66-74.

WTO and Basque Culinary Center (2019), Guidelines for the Development of Gastronomy Tourism, UNWTO, Madrid, DOI: https://doi.org/10.18111/9789284420957

www.maybir.org.tr/aricilik-muzesi-kitapcik [Erişim Tarihi: 12.12.2018].

www.tuik.gov.tr/ PreIstatistikTablo.do?istab_id=69, (“[XLS]45_t17” başlıklı belge), [Erişim Tarihi: 26.12.2018].

Yılmaz Erkovan, N. (2018). Gazipaşa Arı Serenleri. TÜBA-KED Türkiye Bilimler Akademisi Kültür Envanteri Dergisi, TÜBA, (18), 83-100.

Yılmaz, H. ve Şenel, P. (2014). Turistik Bir Çekicilik Olarak Gastronomi Müzeleri, 499-510. İçinde: Kılıçlar, A. (Ed.), 15. Ulusal Turizm Kongresi, Engelsiz Turizm Kongre Kitabı, G.Ü., Turizm Fakültesi: Ankara. 
Zalesskaya, V. N. (1990). Byzantine White-Clay Painted Bowls and Cylix-Type Cups, 215-224. In: Morris, R. (Ed.), Church of People in Byzantium: Twentieth Spring Symposium of Byzantine Studies. Birmingham, Manchester.

Zander, E. (1975). Der Honig. Herkunft, Gewinnung, Eigenschaften und Untersuchung des Honigs. Handbuch der Bienenkunde 6, Verlag Eugen Ulmer: Stuttgart. André, J. (1961). L'Alimentation et la cusine a Rome, Paris. 